\title{
Article \\ A Comprehensive Weight-Based Severity Evaluation Method of Voltage Sag in Distribution Networks
}

\author{
Xiaohan Guo ${ }^{1}$, Yong $\mathrm{Li}^{1}{ }^{1} * \mathbb{D}$, Shaoyang Wang ${ }^{1}$, Yijia Cao ${ }^{2}$, Mingmin Zhang ${ }^{1}$, Yicheng Zhou ${ }^{3}$ and \\ Nakanishi Yosuke ${ }^{3}$ \\ 1 College of Electrical and Information Engineering, Hunan University, Changsha 410082, China; \\ guoxiaohan72@hnu.edu.cn (X.G.); wsy0670@foxmail.com (S.W.); mmzhang1991@hnu.edu.cn (M.Z.) \\ 2 College of Electrical and Information Engineering, Changsha University of Science and Technology, \\ Changsha 410114, China; yjcaohnu@163.com \\ 3 Graduate School of Environment and Energy Engineering, Waseda University, Tokyo 169-8050, Japan; \\ zhouycjp2000@gmail.com (Y.Z.); nakanishi-yosuke@waseda.jp (N.Y.) \\ * Correspondence: yongli@hnu.edu.cn; Tel.: +86-731-8882-2213
}

check for updates

Citation: Guo, X.; Li, Y.; Wang, S.; Cao, Y.; Zhang, M.; Zhou, Y.; Yosuke, N. A Comprehensive Weight-Based Severity Evaluation Method of Voltage Sag in Distribution Networks. Energies 2021, 14, 6434. https:// doi.org/10.3390/en14196434

Academic Editors: Marcelo Cabral Cavalcanti, Leonardo Rodrigues Limongi and Gustavo Medeiros de Souza Azevedo

Received: 14 August 2021

Accepted: 27 September 2021

Published: 8 October 2021

Publisher's Note: MDPI stays neutral with regard to jurisdictional claims in published maps and institutional affiliations.

Copyright: (c) 2021 by the authors. Licensee MDPI, Basel, Switzerland. This article is an open access article distributed under the terms and conditions of the Creative Commons Attribution (CC BY) license (https:// creativecommons.org/licenses/by/ $4.0 /)$.

\begin{abstract}
With the increasing use of sensitive loads in frequency converters and in relays in distribution networks, voltage sag has become a major power quality issue that urgently needs to be solved. For the purpose of improving the understanding of voltage sag severity in distribution networks, a comprehensive weight-based severity evaluation method of voltage sag is presented in this paper. First, a multi-side index system that takes into account the combined influence of the source, network, and the load is established. A comprehensive weight method, which combines the improved analytic hierarchy process (IAHP) and the entropy method, is then adopted to determine the index weight. The weight of each index and the degree of superiority are linearly weighted to obtain the severity of voltage sag at different observation points. Finally, the effectiveness of the proposed method is verified using a distribution network model established in DIgSILENT PowerFactory (15.1.7, Gomaringen, Germany).
\end{abstract}

Keywords: voltage sag; index evaluation; analytic hierarchy process; entropy method; severity evaluation

\section{Introduction}

Voltage sag, which can last from half the grid frequency cycle to 1 minute, is one of the most pervasive power quality problems at present [1,2]. Voltage sag can be caused by motors starting up, high-capacity load switching, transformer energization, or a short circuit in a power system, which may result in equipment malfunctioning and can lead to significant economic losses [3-6]. Factors considered in existing studies pertaining to severity assessment methods for voltage sag issues in distribution networks are not objective and comprehensive. Due to this, it is necessary to find a more appropriate method to evaluate the severity of voltage sags, which facilitates a more useful perspective on the problem of voltage sags in distribution networks.

Research on the severity of voltage sag and relevant evaluation indexes has attracted many scholars' attention. The IEEE P1564 standard provides a framework for voltage sag evaluation [7]. For a single voltage sag event, the common indexes can include the voltage sag magnitude severity index $\left(M_{S I}\right)$, the duration severity index $\left(D_{S I}\right)$, the energy index, the system average RMS frequency index as well as the (SARFI) index, etc. [8].

The analytic hierarchy process (AHP), the optimal sequence diagram method, the entropy method, and the energy function method are most often selected to calculate the weight in the evaluation process of voltage sag severity. A study in the literature [8] uses the multi-objective decision-making analytic hierarchy process to obtain the index weight and introduces user satisfaction into the evaluation criteria of voltage sag severity. 
In a further study in the literature [9], the entropy weight method and the coefficient of the variation method are used to calculate the combined weight of the indexes, and a comprehensive evaluation method for voltage sag severity based on the TOPSIS model is established. An indicator system overviewing power line characteristics and environmental effects is established in study [10], where the BPA program is used to produce a Monte Carlo simulation. However, the outlined methods in the reviewed literature are unable to comprehensively consider objectiveness and subjectiveness, and therefore their weight calculations are, to some extent, biased.

In [11], the authors propose a voltage sag severity evaluation method for the network side by considering the influence of the voltage tolerance curve and the sag types. In [12], a significant index to describe the severity of voltage sags on both the network side and the load side is designed. An evaluation method for the severity of voltage sag is proposed in [13] by comparing the size of the gray relational grade of each node on the network side and the load side. The index systems established in the literature discussed only consider the network side and load side indexes. That is to say, the established index systems presented in these studies are not comprehensive. The common issue in the literature is that all types of voltage sags are regarded only as single-phase voltage sags, resulting in an insufficient evaluation.

In response to the aforementioned problems, the research in this paper focuses on the following aspects:

(1) The proposal of a multi-side index system that comprehensively considers the indexes from the source, the network, and the load combined.

(2) The improved analytic hierarchy process (IAHP) is combined with the entropy weight method to form a comprehensive weight method (CWM) through both subjective and objective factors.

(3) The severity of voltage sag under different fault types is calculated, and the influence of voltage sag caused by different fault types on sensitive equipment is evaluated.

This paper is organized as follows: the multi-side index system is established in Section 2; in Section 3, CWM is introduced; Section 4 provides the simulation details followed by the test results; lastly, Section 5 is the conclusion.

\section{Establishment of Multi-Side Index System}

In order to evaluate voltage sag, a wide range of influential factors must be considered. For this reason, this paper establishes a multi-side index system that divides the influence factors into three groups (i.e., the source side, the network side, and the load side), as shown in Figure $1[14,15]$.

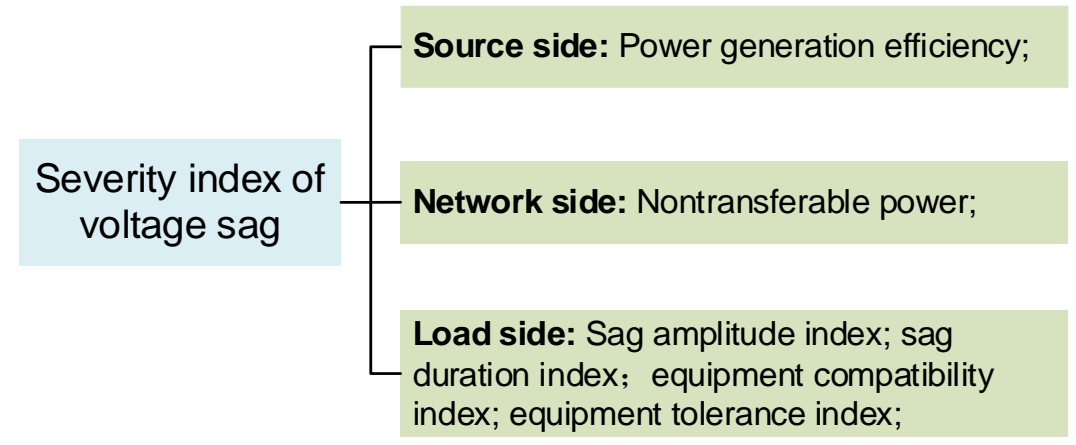

Figure 1. Voltage sag severity index system.

\subsection{Source Side Index}

When voltage sag occurs, the eddy current loss, hysteresis loss, and copper loss of the generator set increase, resulting in a decreased power generation efficiency. The power 
generation efficiency, $\eta$, shown in Equation (1), needs to be taken into consideration as an index on the source side.

$$
\eta=\frac{P_{C}}{P_{L}} \times 100 \%
$$

where $P_{c}$ is motor output power and $P_{L}$ is motor input power.

\subsection{Network Side Index}

When under the conditions of reduced transmission power and limited transmission capacity, voltage sag can seriously affect the reliability of a user's power consumption $[16,17]$. Considering the loss of the transmission power caused by voltage sag as a reference, the index of non-transferable power is proposed [18]. Non-transferable power $\Delta E$ is calculated as follows:

$$
\Delta E=\int_{t_{o n}}^{t_{o n}+T} \Delta P d t
$$

where $\Delta P$ is the instantaneous reduction of load active power, $T$ is the duration of voltage sag, and $t_{o n}$ is the start time of voltage sag.

\subsection{Load Side Index}

Due to differences in the sensitivity, the application type and the working conditions of new and old equipment, it is hard to accurately assess the impact of voltage sags. Regarding its influence on the load side, four load side indexes are defined as follows:

1. Voltage sag magnitude severity index $\left(M_{S I}\right)$. The $M_{S I}$ can be calculated using the following equation:

$$
M_{S I}=\left\{\begin{array}{cc}
0, & d>U_{\max } \\
\left(U_{\max }-d\right) \times\left(\frac{100}{U_{\max }-U_{\min }}\right), & U_{\min } \leq d \leq U_{\max } \\
100, & d<U_{\min }
\end{array}\right.
$$

where $d$ is the amplitude of voltage sags, and $U_{\min }$ and $U_{\max }$ are the upper and lower limits of the voltage sag amplitude on sensitive equipment.

2. Duration severity index $\left(D_{S I}\right)$

$D_{S I}$ is obtained using the following equation:

$$
D_{S I}=\left\{\begin{array}{cc}
0, & t<T_{\min } \\
\left(t-T_{\min }\right) \times\left(\frac{100}{T_{\max }-T_{\min }}\right), & T_{\min } \leq t \leq T_{\max } \\
100, & t>T_{\max }
\end{array}\right.
$$

where $t$ is the duration of voltage sags, and $T_{\min }$ and $T_{\max }$ are the upper and lower limits of voltage sag duration on sensitive equipment.

3. Equipment incompatible index $\left(E_{I C}\right)$

The equipment tolerance index is calculated based on the Semiconductor Equipment and Materials International (SEMI F47) curve. Figure 2 shows the SEMI F47 curve; when the voltage sag magnitude is lower than the value on the curve, that is, when $E_{I C}$ is greater than 1 , it means that the voltage sag has a lesser effect on the device; it also shows that when the voltage sag magnitude is on the curve, $E_{I C}$ is 1 . Further, if the voltage sag magnitude is higher than the value of curve, the voltage sag causes damage to the device [19-22]. The calculation of $E_{I C}$ is shown in the following formula:

$$
E_{I C}=\frac{1-U(t)}{1-U_{\text {curve }(t)}}
$$

where $U(t)$ is the voltage sag magnitude; $U_{\text {curve }}(t)$ is the voltage tolerance magnitude, according to the voltage sag tolerance curve, when the duration of voltage sag is $t$. 


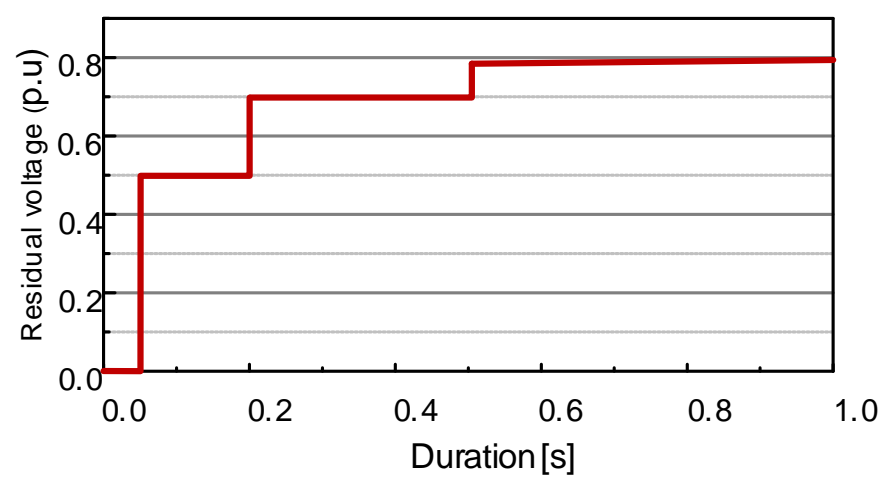

Figure 2. Sensitive equipment SEMI F47 curve.

\section{Calculation of Voltage Sag Index Weight Based on the Comprehensive Weight Method}

IAHP is a method that makes a qualitative and quantitative analysis of the decisionmaking problem. The entropy weight method determines the evaluation weight based on sample data. The following section uses the comprehensive weight method, combining IAHP and the entropy method, in order to integrate the objectivity and subjectivity of the weight calculation, and thereby better evaluate voltage sag severity. The five indexes obtained in Section 2 are classified and used for the superiority matrix calculation. In this way, the weight of subsequent indexes can be derived.

\subsection{Construction of Relative Superiority Matrix}

By making the various indexes of voltage sag targets in multi-objective decision making, the problem of voltage sag severity evaluation becomes a multi-objective decisionmaking problem. Relative superiority refers to the 'excellent' degree of each index. According to the characteristics of a given target, it determines the category of the target, and uses the concept of approximate membership to describe relative superiority through the knowledge of fuzzy mathematics. The established superiority matrix is named $\mu_{5 \times 4}$, which means that there are five indicators and four observation points. In order to calculate the relative superiority degree of each index, this paper divides five indexes categorized into two target types, i.e., cost-based and benefit-based indexes. The matrix of superiority is composed of the superiority degrees of two index types, and the structure is as follows:

$$
\mu_{5 \times 4}=\left[\begin{array}{c}
\mu_{1 \times 4}^{\text {benefit }} \\
\mu_{4 \times 4}^{\text {cos } t}
\end{array}\right]
$$

1. Cost-based index. $\Delta E, M_{S I}, E_{I C}$ and $D_{S I}$ are classified as cost-based indexes. A small attribute value indicates a good index. Its relative superiority degree, $\mu_{i j}{ }^{\text {cost }}$, is expressed as:

$$
\mu_{i j}^{\cos t}=1-x_{i j} /\left(x_{i \max }+x_{i \min }\right)
$$

where $x_{i j}$ is the measured value of the $i$ index of the $j$ observation point, and $x_{i \min }$ and $x_{i \text { max }}$ are the minimum and maximum of measured values at each of the monitoring points of the index $x_{i}$, respectively.

2. Benefit-based index. $\eta$ is classified as a benefit-based index. The higher the attribute value, the better the index. Its relative superiority degree, $\mu_{i j}{ }^{\text {benefit }}$, is expressed as:

$$
\mu_{i j}^{\text {benefit }}=x_{i j} /\left(x_{i \max }+x_{i \min }\right)
$$

Figure 3 represents a flow chart of superiority matrix construction. Firstly, the five indexes proposed in Section 2 are classified, according to their respective attributes, into either a cost-based index or a benefit-based index. The relative superiority degree, $\mu_{i j}$, of each index, $x_{i}$, was calculated at different observation points, and then each specific $\mu_{i j}$ 
value calculated was used to construct the superiority matrix. A larger value of $\mu_{i j}$ in the matrix indicates a better index.

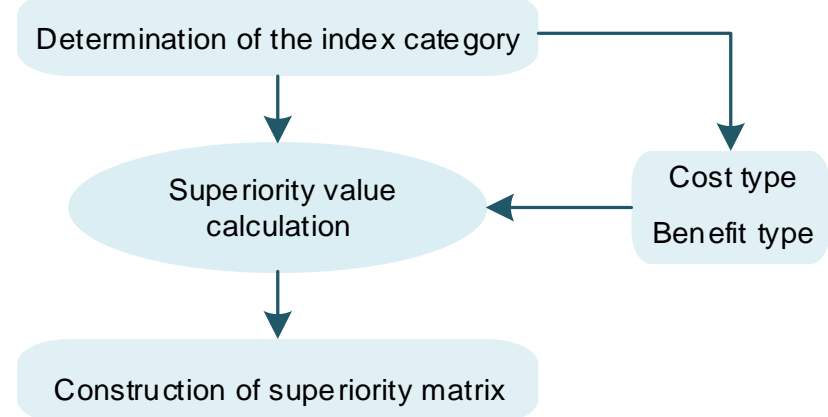

Figure 3. Flow chart of superiority matrix construction.

\subsection{Calculation of IAHP Weight}

1. Calculation of the judgmental weight

Observation points with a small difference in the voltage sag index have little effect on the voltage sag severity and these indexes should therefore be assigned a small weight. Conversely, the observation points with large differences in the voltage sag index present indexes that will play an important role in the voltage sag severity and should therefore be given a large weight.

After obtaining their relative superiority matrix, $\mu_{i j}$, a method of maximizing the deviation is used to calculate the judgmental weight, $p_{i}$, of each index [14]. The judgmental weight, $p_{i}$, can be calculated as follows:

$$
p_{i}=\frac{\sum_{j=1}^{n} \sum_{k=1}^{n}\left|\mu_{i j}-\mu_{i k}\right|}{\sum_{i=1}^{m} \sum_{j=1}^{n} \sum_{k=1}^{n}\left|\mu_{i j}-\mu_{i k}\right|}
$$

In the above formula, $j$ and $k$ represent the corresponding observation points; I $\mu_{i j}$ $-\mu_{i k} \mid$ represents the absolute value of the superiority deviation of index $i$ between the observation point $k$ and the observation point $j$.

2. Construction of judgmental matrix

The judgmental weights are compared in pairs to determine the degree of importance, $r_{i j}$, and then each obtained $r_{i j}$ is used to construct a judgmental matrix, $\left(r_{i j}\right)_{n \times n}$. The judgmental weight, $p_{i}$, corresponds to the voltage sag index, $T_{i}$. Further, $r_{i j}$ is defined as the importance degree coefficient of index $T_{i}$ and index $T_{j}$, ranging from 1 to $9 . n$ represents the order of the matrix, which is equal to the number of indexes. The specific values of judgmental matrix coefficients are shown in Table 1.

Table 1. Coefficient determination of the judgmental matrix.

\begin{tabular}{ccc}
\hline Comparison of Judgmental Weights of Various Indexes & Coefficient Value $r_{i j}$ & Meaning \\
\hline $0 \leq p_{i}-p_{j}<0.03$ & 1 & $T_{i}$ and $T_{j}$ are equally important. \\
$0.03 \leq p_{i}-p_{j}<0.06$ & 2 & The importance of $T_{i}$ and $T_{j}$ is between 1 and 3. \\
$0.06 \leq p_{i}-p_{j}<0.09$ & 3 & $T_{i}$ is slightly more important than $T_{j}$. \\
$0.09 \leq p_{i}-p_{j}<0.12$ & 4 & The importance of $T_{i}$ and $T_{j}$ is between 3 and 5. \\
$0.12 \leq p_{i}-p_{j}<0.15$ & 5 & $T_{i}$ is obviously more important than $T_{j}$. \\
$0.15 \leq p_{i}-p_{j}<0.18$ & 6 & The importance of $T_{i}$ and $T_{j}$ is between 5 and 7. \\
$0.18 \leq p_{i}-p_{j}<0.21$ & 7 & $T_{i}$ is stronger than $T_{j}$. \\
$0.21 \leq p_{i}-p_{j}<0.24$ & 8 & The importance of $T_{i}$ and $T_{j}$ is between 7 and 9. \\
$0.24 \leq p_{i}-p_{j}<1$ & 9 & $T_{i}$ is extremely important compared to $T_{j}$. \\
\hline
\end{tabular}


3. Verification of the consistency

The consistency index is represented by $C_{I}$, and the greater the $C_{I}$, the stronger the consistency. The definition of $C_{I}$ is as follows:

$$
C_{I}=\frac{\lambda_{\max }-n}{n-1}
$$

where $n$ is the order of the judgmental matrix, and $\lambda_{\max }$ is the maximum eigenvalue of the judgmental matrix. When $C_{I}=0$, the matrix has complete consistency; when $C_{I}$ is close to 0 , the matrix has better consistency; when $C_{I}$ is further from 0 , the matrix has a worse consistency.

In order to judge whether $C_{I}$ meets the requirements, the random index, $R_{I}$, is introduced, which can be calculated as follows:

$$
R_{I}=\frac{C_{I 1}+C_{I 2}+\cdots \cdots+C_{I n}}{n}
$$

The relationship between the size of the random consistency index, $R_{I}$, and the order, $n$, of the judgmental matrix is shown in Table 2.

Table 2. Standard value of random consistency index, $R_{I}$.

\begin{tabular}{ccccccccc}
\hline Matrix Order & $\mathbf{1}$ & $\mathbf{2}$ & $\mathbf{3}$ & $\mathbf{4}$ & $\mathbf{5}$ & $\mathbf{6}$ & $\mathbf{7}$ & $\mathbf{8}$ \\
\hline$R_{I}$ & 0 & 0 & 0.58 & 0.90 & 1.12 & 1.24 & 1.32 & 1.41 \\
\hline
\end{tabular}

Finally, the calculated $C_{I}$ is compared with index $R_{I}$, and the test coefficient, $C_{R}$, is obtained. The calculation formula is as follows:

$$
C_{R}=\frac{C_{I}}{R_{I}}
$$

If $C_{R}<0.1$, the consistency requirement is met and if not, it is returned for the construction of a judgmental matrix (Section 3.2 (2)).

4. Calculation of the IAHP weight

This step determines the IAHP weight, $c_{i}$, which is calculated as follows:

$$
c_{i}=\left(\prod_{j=1}^{n} r_{i j}\right)^{1 / n} / \sum_{i=1}^{n}\left(\prod_{j=1}^{n} r_{i j}\right)^{1 / n}, c_{j}=\left(c_{i}\right)^{T}
$$

\subsection{Calculation of Entropy Weight}

1. Standardization of the judgmental matrix

The standardized matrix is denoted as $Q=\left(q_{i j}\right)_{n \times n}$, and the calculation formula of the standardized judgmental matrix coefficient, $q_{i j}$, is as follows:

$$
q_{i j}=r_{i j} / \sum_{i=1}^{n} r_{i j}
$$

2. Information entropy

After the judgmental matrix is standardized, the information entropy is calculated and denoted as $e_{j}$. The information entropy calculation formula is as follows:

$$
e_{j}=-\frac{1}{\ln n} \sum_{i=1}^{n} q_{i j} \ln q_{i j}, j=1 \sim n
$$




\section{Entropy weight}

The entropy weight is an index weight value calculated using the entropy method, and the entropy weight is recorded as $a_{j}$. The calculation formula is as follows:

$$
a_{j}=\left(1-e_{j}\right) /\left(n-\sum_{j=1}^{n} e_{j}\right), j=1 \sim n
$$

\subsection{Calculation of the Comprehensive Weight}

The IAHP weight and the entropy weight are combined to obtain the comprehensive weight. The comprehensive weight is recorded as $\omega_{j}$ and can be written as follows:

$$
\omega_{j}=c_{j} a_{j} / \sum_{j=1}^{n} c_{j} a_{j}
$$

\subsection{Evaluation of the Severity Level of Voltage Sag}

The index superiority degree and index weight of each observation point are linearly weighted in order to obtain the voltage sag severity, $y_{j}$, at each observation point, and then the severity, $y_{j}$, is found. The voltage sag severity, $y_{j}$, at observation point $j$ is as follows:

$$
y_{j}=\sum_{i=1}^{5} q_{i} \times \mu_{i j}
$$

According to Equation (18), the evaluation value of voltage sag severity at each observation point can be calculated.

Thus, the degree of voltage sag severity at each observation point can be obtained. This paper divides the severity of voltage sags into five levels:

- $\quad$ Level $5\left(y_{j}=0 \sim 0.2\right)$ means that voltage sag has a high-level impact on users, and if not handled, it will cause equipment damage and economic loss;

- Level $4\left(y_{j}=0.2 \sim 0.4\right)$ means that voltage sag will have a greater impact on users and may cause damage to some sensitive equipment;

- Level $3\left(y_{j}=0.4 \sim 0.6\right)$ : means that voltage sag will cause sensitive equipment to be damaged, and will harm some sensitive equipment;

- Level $2\left(y_{j}=0.6 \sim 0.8\right)$ means that users should be reminded when/if voltage sag occurs;

- $\quad$ Level $1\left(y_{j}=0.8 \sim 1\right)$ means that voltage sag has almost no influence on users.

The calculation process to determine the voltage sag severity is shown in Figure 4. 


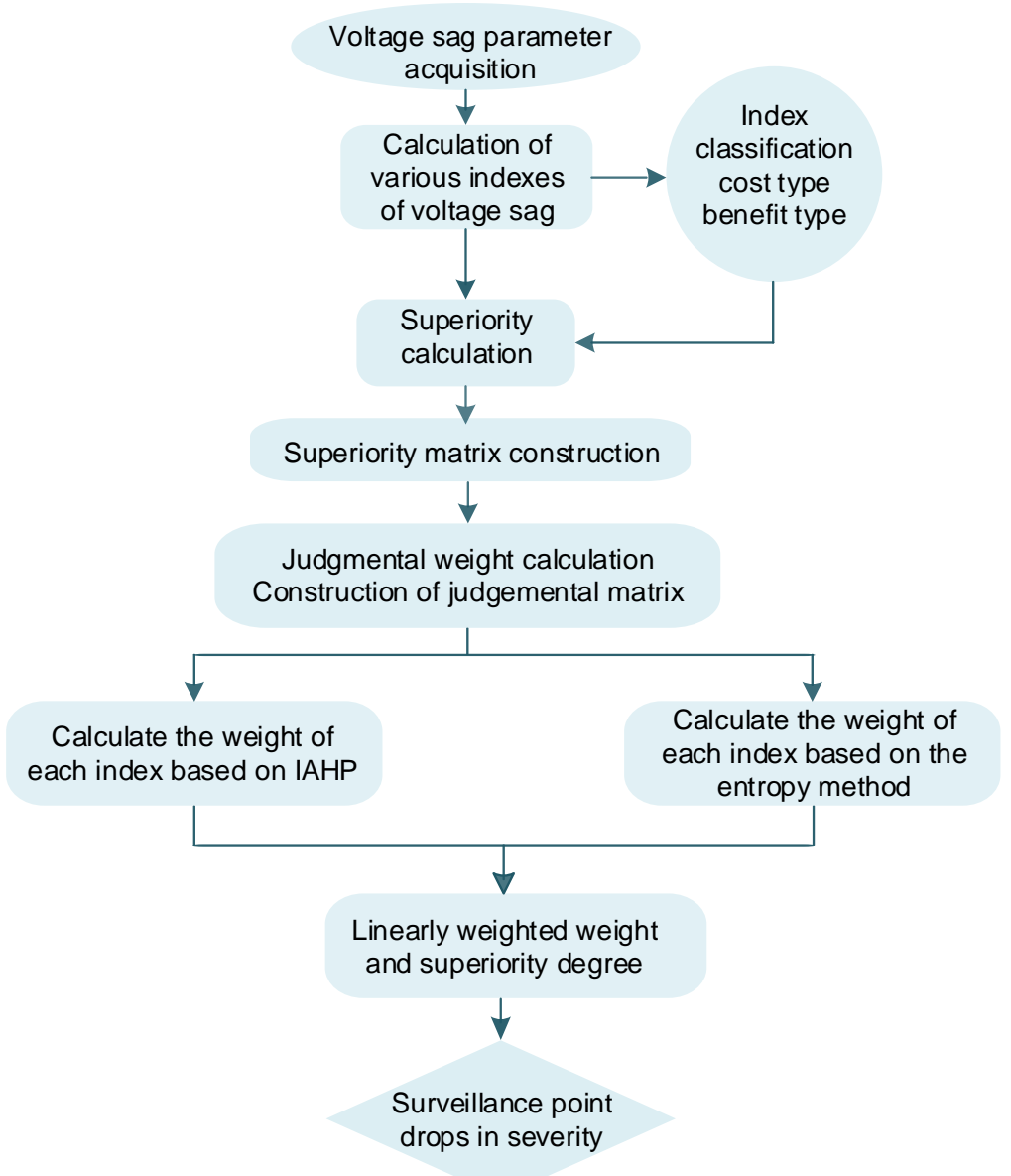

Figure 4. Flow chart of voltage sag severity calculation.

\section{Case Study}

In accordance with the proposed method, the industrial distribution network model in PowerFactory is used for the simulations. As shown in Figure 5, the system voltage levels are $110 \mathrm{kV}, 10 \mathrm{kV}$, and $6.6 \mathrm{kV}$. Three observation points are established in the figure, and it is assumed that each observation point is set with three types of sensitive equipment. The three types of sensitive equipment are selected based on the industrial distribution network, including a PLC (programmable logic controller), an ASD (adjustable speed device), and a PC (personal computer). Voltage amplitude and voltage duration limit values of the three typical sensitive equipment types are shown in Table 3 [23-26].

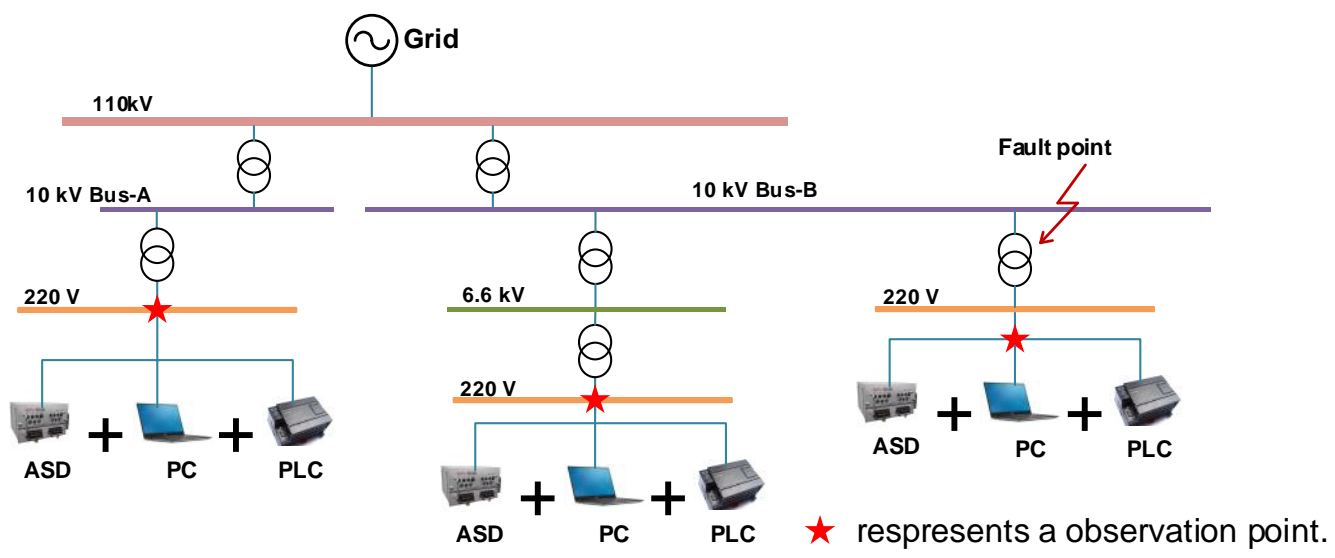

Figure 5. Industrial distribution network. 
Table 3. Sensitive equipment's voltage and duration limits.

\begin{tabular}{ccccc}
\hline Equipment Type & $U_{\max }(\mathbf{p u})$ & $U_{\min }(\mathbf{p u})$ & $T_{\max } / \mathbf{m s}$ & $T_{\min } / \mathbf{m s}$ \\
\hline PLC & 0.90 & 0.30 & 400 & 20 \\
ASD & 0.71 & 0.59 & 175 & 15 \\
PC & 0.63 & 0.46 & 205 & 40 \\
\hline
\end{tabular}

At the fault point, three types of fault simulations, including single-phase short fault (SPSF), two-phase short fault (TPSF), and three-phase short fault (THPSF), are performed, respectively. Based on Appendix $A$, the specific values of five indexes on the source, network, and load side are calculated. The calculation results are shown in Tables 4-6.

Table 4. Index value of SPSF.

\begin{tabular}{cccccc}
\hline Observation Point & $\boldsymbol{\eta} / \%$ & $\boldsymbol{\Delta} \boldsymbol{E} / \mathbf{J} \times \mathbf{1 0}^{\mathbf{3}}$ & $\boldsymbol{M}_{\boldsymbol{S I}}$ & $\boldsymbol{D}_{\boldsymbol{S I}}$ & $\boldsymbol{E}_{\boldsymbol{I C}}$ \\
\hline PLC of $10 \mathrm{kV}$ bus-B & 57.18 & 1.8448 & 35.3833 & 30.7105 & 0.6246 \\
ASD of $10 \mathrm{kV}$ bus-B & 57.18 & 1.8448 & 18.5833 & 76.0625 & 0.6246 \\
PC of $10 \mathrm{kV}$ bus-B & 57.18 & 1.8448 & 0 & 58.6061 & 0.6246 \\
PLC of $10 \mathrm{kV}$ bus-A & 57.20 & 9.5185 & 35.4833 & 33.3421 & 0.6258 \\
ASD of $10 \mathrm{kV}$ bus-A & 57.20 & 9.5185 & 19.0833 & 82.3125 & 0.6258 \\
PC of $10 \mathrm{kV}$ bus-A & 57.20 & 9.5185 & 0 & 64.6667 & 0.6258 \\
PLC of $6.6 \mathrm{kV}$ bus & 65.60 & 0.0229 & 17.8833 & 1.7632 & 0.2073 \\
ASD of $6.6 \mathrm{kV}$ bus & 65.60 & 0.0229 & 0 & 7.3125 & 0.2073 \\
PC of $6.6 \mathrm{kV}$ bus & 65.60 & 0.0229 & 0 & 0 & 0.2073 \\
\hline
\end{tabular}

Table 5. Index value of TPSF.

\begin{tabular}{cccccc}
\hline Observation Point & $\boldsymbol{\eta} / \boldsymbol{\%}$ & $\boldsymbol{\Delta} \boldsymbol{E} / \mathbf{J} \times \mathbf{1 0}^{\mathbf{3}}$ & $\boldsymbol{M}_{\boldsymbol{S I}}$ & $\boldsymbol{D}_{\boldsymbol{S I}}$ & $\boldsymbol{E}_{\boldsymbol{I C}}$ \\
\hline PLC of $10 \mathrm{kV}$ bus-B & 50.33 & 2.1399 & 56.4670 & 43.8680 & 0.8776 \\
ASD of $10 \mathrm{kV}$ bus-B & 50.33 & 2.1399 & 100 & 100 & 0.8776 \\
PC of $10 \mathrm{kV}$ bus-B & 50.33 & 2.1399 & 40.4710 & 88.9090 & 0.8776 \\
PLC of $10 \mathrm{kV}$ bus-A & 50.35 & 11.0409 & 56.5333 & 49.1316 & 1.4640 \\
ASD of $10 \mathrm{kV}$ bus-A & 50.35 & 11.0409 & 100 & 100 & 1.4640 \\
PC of $10 \mathrm{kV}$ bus-A & 50.35 & 11.0409 & 40.7059 & 100 & 1.4640 \\
PLC of $6.6 \mathrm{kV}$ bus & 56.30 & 0.0291 & 33.2500 & 9.6579 & 0.5990 \\
ASD of $6.6 \mathrm{kV}$ bus & 56.30 & 0.0291 & 7.9167 & 26.0625 & 0.5990 \\
PC of $6.6 \mathrm{kV}$ bus & 56.30 & 0.0291 & 0 & 10.1212 & 0.5990 \\
\hline
\end{tabular}

Table 6. Index value of THPSF.

\begin{tabular}{cccccc}
\hline Observation Point & $\boldsymbol{\eta} / \mathbf{\%}$ & $\boldsymbol{\Delta} \boldsymbol{E} / \mathbf{J} \times \mathbf{1 0}^{\mathbf{3}}$ & $\boldsymbol{M}_{\boldsymbol{S I}}$ & $\boldsymbol{D}_{\boldsymbol{S I}}$ & $\boldsymbol{E}_{\boldsymbol{I C}}$ \\
\hline PLC of $10 \mathrm{kV}$ bus-B & 50.33 & 2.1399 & 56.4670 & 43.8680 & 0.8776 \\
ASD of $10 \mathrm{kV}$ bus-B & 50.33 & 2.1399 & 100 & 100 & 0.8776 \\
PC of $10 \mathrm{kV}$ bus-B & 50.33 & 2.1399 & 40.4710 & 88.9090 & 0.8776 \\
PLC of $10 \mathrm{kV}$ bus-A & 50.35 & 11.0409 & 56.5333 & 49.1316 & 1.464 \\
ASD of $10 \mathrm{kV}$ bus-A & 50.35 & 11.0409 & 100 & 100 & 1.464 \\
PC of $10 \mathrm{kV}$ bus-A & 50.35 & 11.0409 & 40.7059 & 100 & 1.464 \\
PLC of $6.6 \mathrm{kV}$ bus & 56.30 & 0.0291 & 33.2500 & 9.6579 & 0.599 \\
ASD of $6.6 \mathrm{kV}$ bus & 56.30 & 0.0291 & 7.9167 & 26.0625 & 0.599 \\
PC of $6.6 \mathrm{kV}$ bus & 56.30 & 0.0291 & 0 & 10.1212 & 0.599 \\
\hline
\end{tabular}

In view of the calculated indexes, the judgmental weights corresponding to each index are calculated through the method of maximizing deviation. The judgmental weights are as follows Tables 7-9: 
Table 7. Judgmental weight of SPSF.

\begin{tabular}{cccccc}
\hline Index Category & $\boldsymbol{D}$ & $\boldsymbol{\Delta E}$ & $\boldsymbol{M}_{\boldsymbol{S I}}$ & $\boldsymbol{D}_{S I}$ & $\boldsymbol{E}_{I C}$ \\
\hline Weight & 0.0210 & 0.2446 & 0.2927 & 0.2876 & 0.1541 \\
\hline
\end{tabular}

Table 8. Judgmental weight of TPSF.

\begin{tabular}{cccccc}
\hline Index Category & $\boldsymbol{D}$ & $\boldsymbol{\Delta E}$ & $\boldsymbol{M}_{\boldsymbol{S I}}$ & $\boldsymbol{D}_{\text {SI }}$ & $\boldsymbol{E}_{I C}$ \\
\hline Weight & 0.0179 & 0.3183 & 0.2626 & 0.2671 & 0.1341 \\
\hline
\end{tabular}

Table 9. Judgmental weight of THPSF.

\begin{tabular}{cccccc}
\hline Index Category & $\eta$ & $\Delta E$ & $M_{S I}$ & $D_{S I}$ & $E_{I C}$ \\
\hline Weight & 0.2133 & 0.4000 & 0.0429 & 0.1799 & 0.1639 \\
\hline
\end{tabular}

The values of judgment weights can be substituted into Table 1, so that three judgment matrices for three fault types can be obtained. The judgment matrix under different fault types is substituted into Equation (15) to obtain the information entropy, which is listed in order according to SPSF, TPSF and THPSF: $e_{j}=[0.7026,0.2101,0.1317,0.1317,0.4318]$, $e_{j}=[0.7428,0.1066,0.1720,0.1720,0.4645]$ and $e_{j}=[0.2404,0.1761,0.5810,0.3114,0.3114]$. The entropy weight calculated by Equation (16) is given in the same order as above: $a_{j}=[0.0877,0.2329,0.2560,0.2560,0.1675], a_{j}=[0.0770,0.2673,0.2477,0.2477,0.1602]$ and $a_{j}=[0.2248,0.2438,0.1240,0.2037,0.2037]$.

Two different methods are used to calculate the weight of each index based on the judgmental matrix: one is AHP, and the other is CWM. The weight value selected by AHP does not change with the fault type. However, CWM carries out a weight calculation for each type of fault, while the weight value changes with the actual data. The following table lists the weight values calculated by the two referenced methods.

By linearly weighting the weight values obtained by the two methods in Table 10 and the corresponding coefficients in the superiority degree matrix, the corresponding evaluation values of voltage sag severity can be obtained.

Table 10. Index weight.

\begin{tabular}{ccccc}
\hline Index Category & AHP Weight & $\begin{array}{c}\text { Comprehensive } \\
\text { Weight (SPSF) }\end{array}$ & $\begin{array}{c}\text { Comprehensive } \\
\text { Weight (TPSF) }\end{array}$ & $\begin{array}{c}\text { Comprehensive } \\
\text { Weight (THPSF) }\end{array}$ \\
\hline$\eta$ & 0.0301 & 0.0101 & 0.0086 & 0.1135 \\
$\Delta E$ & 0.1967 & 0.2050 & 0.4433 & 0.7475 \\
$M_{S I}$ & 0.3473 & 0.3657 & 0.2534 & 0.0116 \\
$D_{S I}$ & 0.3473 & 0.3657 & 0.2534 & 0.0637 \\
$E_{I C}$ & 0.0786 & 0.0535 & 0.0413 & 0.0637 \\
\hline
\end{tabular}

In Figures 6-8, the severity evaluation values calculated by AHP and CWM for SPSF and TPSP are found to have little difference, while the severity evaluation values calculated by the two methods for THPSF have a greater difference. This is because, when the comprehensive weight method is adopted, the dynamic changes of index data are considered for weight allocation, and each fault type is weighted once. The comprehensive weight method improves the rationality of the index weight. 


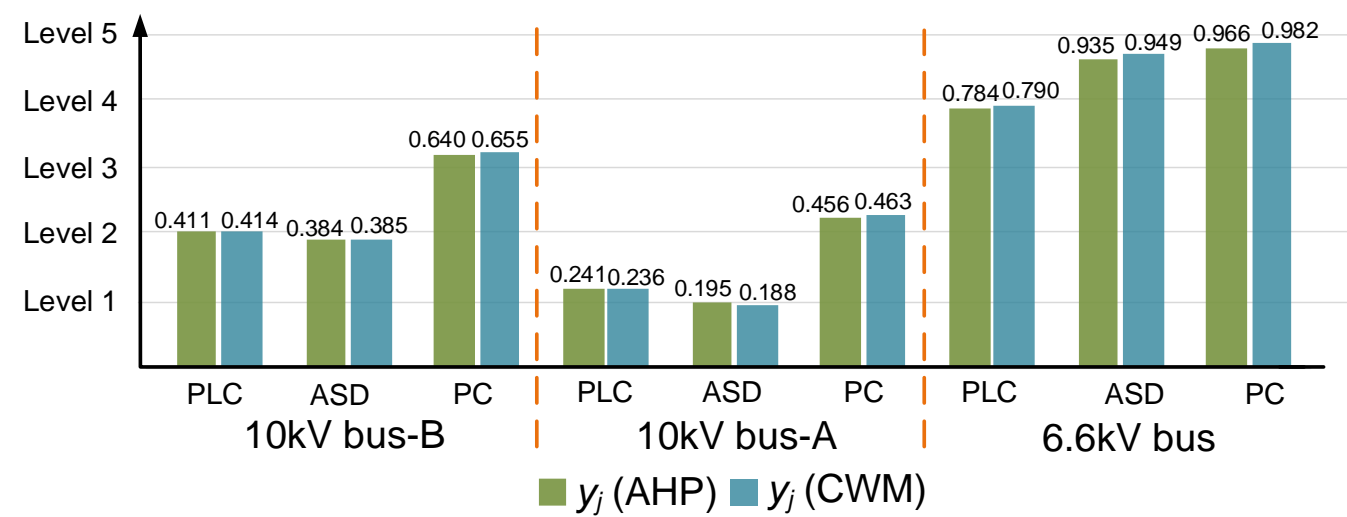

Figure 6. Voltage sag severity level of SPSF.

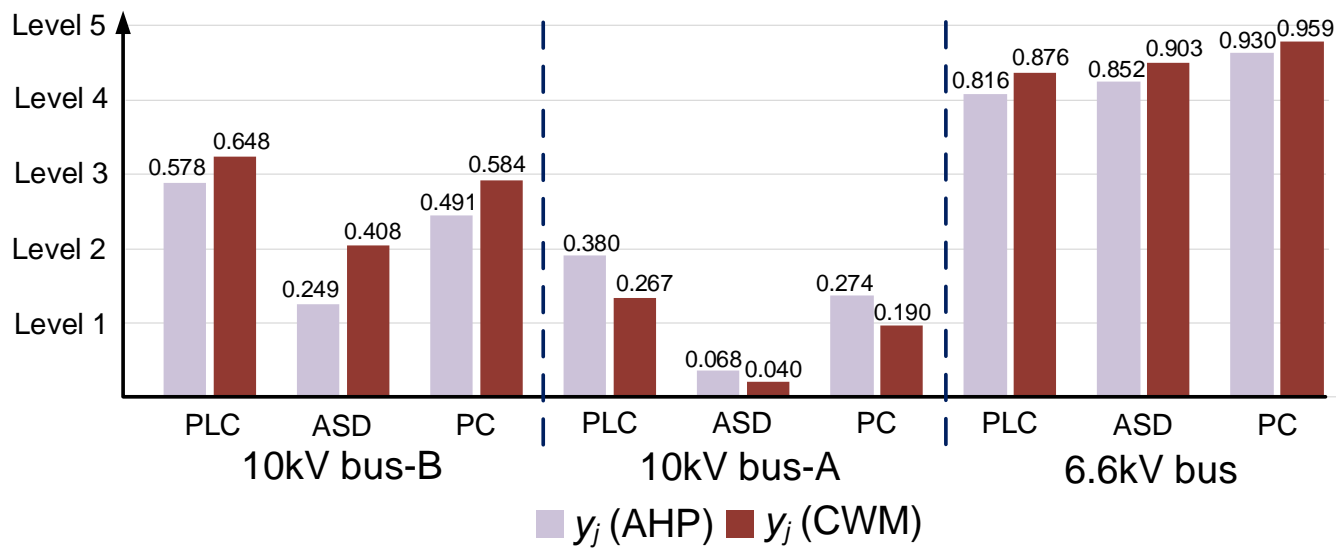

Figure 7. Voltage sag severity level of TPSF.

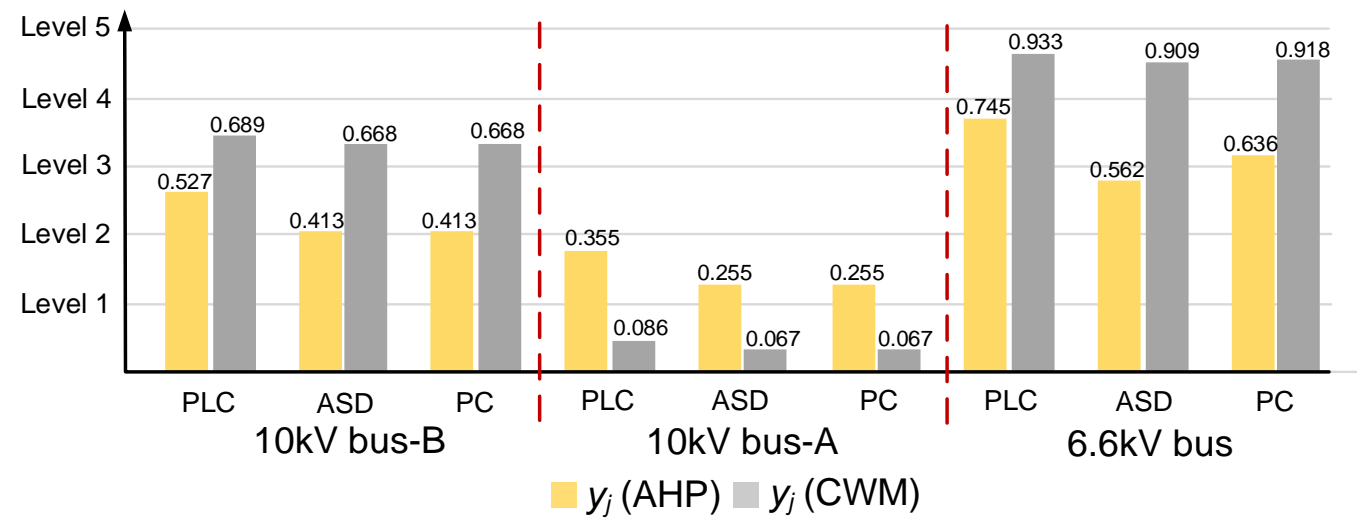

Figure 8. Voltage sag severity level of THPSF.

In order to effectively assess the vulnerability of sensitive equipment when a voltage sag occurs, SPSF, TPSF, and THPSF are considered in the simulation. In each fault type, the severity level of the equipment on the $6.6 \mathrm{kV}$ bus is Level 1 or Level 2. The equipment, when under these two levels, is relatively safe, and the voltage sag has little impact on the equipment. On the contrary, if the sensitive equipment on the $10 \mathrm{kV}$ bus-A is Level 4 or Level 5 for each fault type, voltage sag will have a greater impact on equipment and if it is not managed, it will cause equipment damage and economic losses. Under SPSF and TPSF, the ASD and PLC of $10 \mathrm{kV}$ bus-B are of a high severity level and may cause damage to the equipment. 


\section{Conclusions}

In this paper, a comprehensive index system that integrates multi-side indexes of the source, the network, and the load using the comprehensive weight method to evaluate the voltage sag severity, is presented. The main contributions of this article are as follows:

(1) The proposed multi-side index system has the ability to reduce the potential of the evaluation level of voltage sag severity being overestimated, as can happen when only the load index is considered.

(2) The comprehensive weighting method, by combining the merits of the entropy weight method and IAHP, is proposed to give consideration to both subjective and objective evaluation.

(3) The vulnerability of sensitive equipment under different voltage sag conditions was comprehensively and concretely evaluated by the case studies of different types of circuit faults in the distribution network.

Author Contributions: All the authors made contributions to the concept and design of the article; X.G. is the main author of this work; Y.L. provided good advice and technical guidance for the manuscript; Y.L., S.W., Y.C., M.Z., Y.Z. and N.Y. reviewed and edited the manuscript. All authors have read and agreed to the published version of the manuscript.

Funding: This work was supported in part by the International Science and Technology Cooperation Program of China under Grant 2018YFE0125300, in part by the National Nature Science Foundation of China under Grant 52061130217, in part by the Innovative Construction Program of Hunan Province of China under Grant 2019RS1016, in part by the 111 Project of China under Grant B17016, and in part by the Excellent Innovation Youth Program of Changsha of China under Grant KQ2009037.

Institutional Review Board Statement: Not applicable.

Informed Consent Statement: Not applicable.

Data Availability Statement: Not applicable.

Conflicts of Interest: The authors declare no conflict of interest.

\section{Appendix A}

The sag amplitude, duration, and sag type of each observation point are shown in Table A1.

Table A1. Sag feature information at observation point.

\begin{tabular}{cccc}
\hline Sag Type & Observation Point & Sag Amplitude U/p.u. & Duration $\mathbf{T} / \boldsymbol{m s}$ \\
\hline SPSF & $10 \mathrm{kV}$ bus-B & 0.6877 & 136.7 \\
SPSF & $10 \mathrm{kV}$ bus-B & 0.6871 & 146.7 \\
SPSF & $10 \mathrm{kV}$ bus-B & 0.7927 & 26.7 \\
TPSF & $10 \mathrm{kV}$ bus-A & 0.5612 & 186.7 \\
TPSF & $10 \mathrm{kV}$ bus-A & 0.5608 & 206.7 \\
TPSF & $10 \mathrm{kV}$ bus-A & 0.7005 & 56.7 \\
THPSF & $6.6 \mathrm{kV}$ bus & 0.2630 & 236.7 \\
THPSF & $6.6 \mathrm{kV}$ bus & 0.2627 & 256.7 \\
THPSF & $6.6 \mathrm{kV}$ bus & 0.4830 & 136.7 \\
\hline
\end{tabular}

\section{References}

1. Liu, J.H.; Chen, K.X.; Ma, J.; Xu, C.H.; Wu, J.H. Classification of three-phase voltage dips based on CNN and random forest. Power Syst. Prot. Control 2019, 47, 112-118.

2. Li, Z.M.; Li, W.W.; Pan, T.H. An optimized compensation strategy of DVR for micro-grid voltage sag. Prot. Control Mod. Power Syst. 2016, 1, 10. [CrossRef]

3. Li, S.; Jiang, C.C.; Zhao, Z.Y.; Li, Z.Y. Study of transient voltage stability for distributed photovoltaic power plant integration into low voltage distribution network. Power Syst. Prot. Control 2017, 45, 67-72. 
4. Amir, S.; Mahmud, F.; Matti, L. A General Framework for Voltage Sag Performance Analysis of Distribution Networks. Energies 2019, 12, 2824.

5. Motoki, E.; Filho, J.; da Silveira, P.; Pereira, N.; de Souza, P. Cost of Industrial Process Shutdowns Due to Voltage Sag and Short Interruption. Energies 2021, 14, 2874. [CrossRef]

6. Liu, Q.Y.; Liu, F.; Zou, R.M.; Li, Y. Harmonic Resonance Characteristic of Large-scale PV Plant: Modelling, Analysis and Engineering Case. IEEE Trans. Power Deliv. 2021, 30, 2392-2400.

7. Bollen, M.H.J.; Sabin, D.D. International coordination for voltage sag indices. In Proceedings of the IEEE Power Engineering Society Transmission and Distribution Conference, San Francisco, CA, USA, 21-24 May 2006; IEEE: New York, NY, USA, 2006; pp. 229-234.

8. Chan, J.Y.; Milanovic, J.V. Severity Indices for Assessment of Equipment Sensitivity to Voltage Sags and Short Interruptions. In Proceedings of the 2007 IEEE Power Engineering Society General Meeting, Tampa, FL, USA, 24-28 June 2007; IEEE: New York, NY, USA, 2007; pp. 1-7.

9. Wang, Y.; Dong, Y. Evaluation of voltage sag severity based on multisource causative attribute. In Proceedings of the 2019 IEEE Sustainable Power and Energy Conference (ISPEC), Beijing, China, 21-23 November 2019; IEEE: New York, NY, USA, 2020; pp. 815-820.

10. Yang, J.L.; Xu, Y.H. Comprehensive evaluation method of node voltage sag severity based on TOPSIS model and combination weights. Power Syst. Prot. Control 2017, 45, 88-95.

11. Zeng, J.; Cai, D.Y. A monte carlo assessment method of voltage sags based on combination weight. Power Syst. Technol. 2016, 40, 1469-1475.

12. Xu, Y.H.; Fan, X.G.; Deng, S.Y.; Niu, C.H. A Voltage Sag Severity Evaluation Method for the System Side Which Considers the Influence of the Voltage Tolerance Curve and Sag Type. Energies 2021, 14, 5065. [CrossRef]

13. Zhou, X.; Wang, F.H.; Zhang, J.; Huang, R.H. A voltage sag severity index considering the power system and consumer equipment. In Proceedings of the 2014 IEEE PES General Conference \& Exposition, National Harbor, MD, USA, 27-31 July 2014; IEEE: New York, NY, USA, 2014; pp. 1-5.

14. Pan, L.; Zhang, P.; Yu, X. Comprehensive Evaluation of Node Voltage Sag Severity Considering the Power Grid Side and the User Side. In Proceedings of the 2018 China International Conference on Electricity Distribution (CICED), Tianjin, China, 17-19 September 2018; IEEE: New York, NY, USA, 2018; pp. 467-471.

15. Wu, G.; Zhong, Q.; He, Q.; Xu, Z. Evaluation Method and Probabilistic Index of Voltage Sag Severity Considering Point-on-wave. J. Mod. Power Syst. Clean Energy 2021, 9, 633-638.

16. Chang, H.Y.P.; Gilsoo, J. Systematic Method to Identify an Area of Vulnerability to Voltage Sags. IEEE Trans. Power Deliv. 2017, 32, 1583-1591.

17. Liao, H.; Abdelrahman, S.; Guo, Y.; Milanovic, J. Identification of Weak Areas of Power Network Based on Exposure to Voltage Sags-Part I: Development of Sag Severity Index for Single-Event Characterization. IEEE Trans. Power Deliv. 2015, 30, 2392-2400. [CrossRef]

18. Biswas, S.; Goswami, S.K.; Chatterjee, A. Optimum distributed generation placement with voltage sag effect minimization. Energy Convers. Manag. 2012, 53, 163-174. [CrossRef]

19. Xiao, X.Y.; Chen, W.D.; Yang, H.G.; Li, H.Q. Voltage Sag Frequency Assessment under the Measure of Interval Data of Customer Satisfaction. Proc. CSEE 2010, 30, 104-110.

20. Djokic, S.Z.; Desmet, J.; Vanalme, G.; Milanovic, J.V.; Stockman, K. Sensitivity of personal computers to voltage sags and short interruptions. IEEE Trans. Power Deliv. 2005, 20, 375-383. [CrossRef]

21. Djokic, S.Z.; Stockman, K.; Milanovic, J.V.; Desmet, J.J.M.; Belmans, R. Sensitivity of AC adjustable speed drives to voltage sags and short interruptions. IEEE Trans. Power Deliv. 2005, 20, 494-505.

22. Gupta, C.P.; Milanovic, J.V. Probabilistic assessment of equipment trips due to voltage sags. IEEE Trans. Power Deliv. 2006, 21, 711-718. [CrossRef]

23. Kong, F.; Liu, H.Y. A new fuzzy MADM algorithm based on subjective and objective integrated weights. In Proceedings of the 2007 International Conference on Service Management, Chengdu, China, 9-11 June 2007; IEEE: New York, NY, USA, 2007; pp. 1-6.

24. Wu, Y.; Li, C.; Xu, Y.; Wei, P. Characterizing the tolerance performance of PLCs to voltage sag based on experimental research. In Proceedings of the 2016 IEEE PES Asia-Pacific Power and Energy Engineering Conference (APPEEC), Xi'an, China, 25-28 October 2016; pp. 496-501.

25. Escribano, A.H.; Gómez-Lázaro, E.; Molina-García, A.; Fuentes, J. Influence of voltage dips on industrial equipment: Analysis and assessment. Int. J. Electr. Power Energy Syst. 2012, 41, 87-95. [CrossRef]

26. Djokic, S.; Milanovic, J.; Kirschen, D. Sensitivity of AC Coil Contactors to Voltage Sags, Short Interruptions, and Undervoltage Transients. IEEE Trans. Power Deliv. 2004, 19, 1299-1307. [CrossRef] 